\title{
Análise Física da Água de entrada no Sistema Agroindustrial de Curtume em Maringá- Paraná
}

\author{
Physical Analysis of entry Water in the Agro-industry System of tannery in the city of Maringá- \\ Paraná
}

\author{
Marcelo Estevam' \\ Adriano Willian da Silva" \\ Frederico Fonseca da Silva'"I
}

\section{Resumo}

A avaliação da qualidade da água é de extrema importância para a saúde dos animais, em especial, dos seres humanos. Os parâmetros físicos (condutividade elétrica, dureza total, $\mathrm{pH}$, turbidez, cor aparente, gosto, odor, sólidos totais, sólidos totais dissolvidos e sólidos suspensos totais), na água indicam a qualidade, inclusive, aquela usada para o consumo humano. Por isso, a verificação destes indicadores na água de entrada e saída de umsistema agroindustrial de curtume em Maringá/PR, entre os anos de 2014 a 2017, é importante para a compreensão e estímulo a formas de controle da qualidade da água. Os resultados obtidos e analisados com base na atual legislação ambiental demonstram que a qualidade da água utilizada na agroindústria, no tocante aos parâmetros físicos, respeita as normativas ambientais vigentes, não trazendo prejuízo ao meio ambiente e demonstrando que o processo aplicado no sistema agroindustrial é eficiente sob a ótica ambiental.

Palavras chave: Água; Agroindústria; Parâmetros físicos

\section{Abstract}

Assessment of water quality is extreme importance for the health of animals, especially humans. The physical paraments (electrical conductivity, $\mathrm{pH}$, turbidity, apparent color, taste, smell, total solids, total dissolved solids, total suspended solids), in water indicate the quality, including that used for human consumption. Therefore, a water inspection at the entrance and exit of an agroindustrial cutting system in the city of Maringa (Brazil), between the years 2014 and 2017, is important for a relaxation of water standards. The results were published and published based on the environmental legislation showed that the quality of the water used in the agroindustry, regarding the physical parameters, respects as current environmental regulations, not causing damage to the environment and demonstrating that the process used in the agroindustrial system is efficient from an environmental standpoint.

Keywords: Water; Agroindustry; Physical parameters

\footnotetext{
IFPR - Instituto Federal do Paraná- Campus Curitiba, Curitiba (PR), Brasil. E-mail: marcelo.estevam@ifpr.edu.br

"Instituto Federal do Paraná-Campus Curitiba, Curitiba (PR), Brasil. E-mail:adriano.silva@ifpr.edu.br

I"Instituto Federal do Paraná- Campus Curitiba, Curitiba (PR), Brasil. E-mail: frederico.silva@ifpr.edu.br
} 


\section{Introdução}

O presente estudo é fruto do Projeto de Pesquisa Considerações ambientais a serem desenvolvidas no Curtume Central, na cidade de Maringá (PR) sob a responsabilidade do primeiro autor onde, uma das atividades apresentadas, consistiu em entender a situação atual do processo de entrada e saída da água no sistema agroindustrial de um curtume em Maringá-PR, o que constituiu o estágio inicial do projeto,que tem como finalidadepropor soluções ambientais e viáveis do empreendimento agroindustrial.

No artigoAnálise química da água de entrada no sistema agroindustrial de curtume em Maringá, publicado na revista REMOA, SILVA e SILVA (2018) analisaram osparâmetros químicos considerando a água de entrada no sistema agroindustrial de curtume em Maringá ( $\mathrm{Pa}-$ raná) e concluíram que tais indicadores estão de acordo com a legislação vigente. Agora, neste trabalho, objetiva-se compreender e verificar os impactos do processo agroindustrial nos indicadores físicos da água utilizada na fabricação de couro em uma indústria de Maringá, considerando sua entrada e saída no sistema industrial.

Dessa forma, todo o processo de análise de monitoramento do sistema ambiental de águas residuárias agroindustriais, perpassou, obrigatoriamente, pela qualidade da água de entrada nesse sistema, como forma de se entender as suas variações e todos os processos físicos sujeitos à ela .

Outrossim, ao interpretá-las em separado (água de entrada das águas residuárias), sem jamais desvencilhar-se das interações dos parâmetros entre si, entende-se que toda e qualquer variação de algum dos parâmetros avaliados, seja no âmbito espacial ou temporal, deve ser interpretado objetivando o controle máximo possível, com as suas possíveis análises para cada um dos casos e, em especial, tendo um referencial balizador quanto ao modelo adotado.

Para tanto, considerando que o presente monitoramento e estudo localiza-se na área de influencia da cidade de Maringá, na região noroeste do Paraná, se utilizouda IN-001/06, da SUDERHSA (Superintendência de Desenvolvimento de Recursos Hídricos e Saneamento Ambiental), vinculado ao Instituto das Águas do Paraná, como balizador da legislação estadual; e, as Resoluções 357/05 e 430/11, ambas do CONAMA (Conselho Nacional de Meio Ambiente), como referencial de legislação Federal.

O uso de águas subterrâneas para consumo humano e atividades agroindustriais no Paraná tem se intensificado nos últimos anos devido, principalmente, à escassez da oferta de águas superficiais com boa qualidade e devido ao fácil acesso aos aquíferos que ocorrem na região (ROSA FILHO et al., 2010).

O Aquífero Serra Geral, que toma praticamente todo o Terceiro Planalto Paranaense, é responsável por complementar o abastecimento público de água no município de Maringá e, como observado no banco de dados das Águas Paraná, tem fins comerciais, industriais e também, até o período estudado, para irrigação de pequenas áreas agrícolas que estão dentro do perímetro urbano da cidade. Este apresenta uma série de fraturas, o que aumenta sua capacidade de armazenamento de água e substâncias dissolvidas. A água confinada apresenta-se bicabornatada cálcica e, muito comumente, cálcica-magnesiana, devido a composição da rocha e também do tempo de confinamento desta água neste reservatório natural (ROSA FILHO, 2011).

No Brasil, quando se trata de águas subterrâneas, há duas principais regulamentações que estabelecem diretrizes sobre a qualidade deste recurso, a Resolução CONAMA n 396 de 2008 (BRASIL, 2008) e a Portaria do Ministério da Saúde n 2.914 de 2011 (BRASIL, 2011). Enquanto a primeira dispõe sobre a classificação e enquadramento das águas subterrâneas, a outra abrange procedimentos de controle e de vigilância da qualidade da água para consumo humano e seu padrão de potabilidade. Ambos estabelecem limites para certos parâmetros presentes na água.

Os problemas de degradação da qualidade das águas subterrâneas são mais difíceis de serem superados. Uma vez queheterogeneidades são inerentes aos sistemas de subsuperfície, as zonas de águas subterrâneas degradadas são muito difíceis de detectar (FREEZE e CHERRY, 1979).

Dessa forma, quando da análise e interpretação dos parâmetros no campo dos Resultados e Discussão, a Tabela 1 apresenta a qualidade dos parâmetros físicos da saída da água do poço tubular.

\section{Metodologia}

A metodologia utilizada consistiu em adotar a técnica proposta no Manual Técnico para coleta de amostras de água, publicado pelo Ministério Público de Santa Catarina (s/d) onde, para coleta de águas de poços ou cisternas, objetivando os testes físicos: Usou-se balde de metal onde o mesmo foi muito bem lavado internamente e externamente, em seguida o mesmo foi limpo com álcooletílico hidratado 70 INPM; Submergiu-se o balde na água; Depois do balde cheio, transferiu-se a amostra para o frasco estéril, enchendo com a amostra até $3 / 4$ de sua capacidade e, em seguida, fechou-se bem o frasco.

Após realizar a coleta, identificaram-se os frascos contendo as amostras e preencheu-se a Requisição de Ensaio, onde os mesmos foram armazenados de acordo com o recomendado para as diferentes análises e parâmetros a serem avaliados.

Depois do processo de preservação, todos os frascos foram acondicionadossob refrigeração em uma caixa térmica com gelo comum filtrado, em quantidade suficiente para preencher os espaços vazios da caixa.

O tempo entre a coleta e o recebimento da amostra pelo setor de recepção, foi inferior a 24 horas, tanto para as amostras destinadas.

Para as referências normativas, utilizou-se o Standard Methods for the Examination of Water and Wastewater, $22^{\text {th }}$ Edition (APHA / AWWA). 


\section{Resultado e Discussão}

A Tabela 1 apresenta a qualidade dos parâmetros físicos da água do poço tubular, junto com a média e desvio padrão para aprofundamento das análises sob a ótica temporal. Contudo, os valores expressos são pontuais.

\section{Condutividade Elétrica}

A condutividade elétrica da água representa a facilidade ou a dificuldade de passagem da eletricidade nessa água. Os compostos orgânicos e inorgânicos nelas contida contribuem ou interferem nessa condutividade, de acordo com sua concentração na amostra, e está intimamente ligada ou dependente de outras variáveis tais como $\mathrm{pH}$ e temperatura. Dessa forma, a correta representação da temperatura possui um fator preponderante na medição correta da condutividade elétrica.
Valores de condutividade elétrica da água são utilizados há décadas como indicativos da qualidade da água, com sua representação pelo Sistema Internacional em unidades milisiemens por $\mathrm{cm}^{2}\left(\mathrm{mS} / \mathrm{cm}^{2}\right)$ ou micro Siemens por $\mathrm{cm}\left(\mathrm{uS} . \mathrm{cm}^{-1}\right)$.

Com base no que fora sintetizado na Tabela 1 , observa-se que em setembro de 2014 foram feitas análises de dois diferentes tipos de poços; e, para os anos de 2016 (nos meses de março e maio) e 2017 (em agosto), as amostras si concentraram para o Poço1 (P1) e os valores para esse parâmetro tendem a apresentar pouca flutuação temporal, com exceção para o período de março de 2016 onde, muito provavelmente, as águas que alimentam os lençóis freáticos da região da bacia coletora devam ter diluído os sais contidos na água (conforme extrato da Tabela 1, abaixo).

Seus valores representam a carga mineral presente na água oriunda da geologia local ou regional. Assim, em

Tabela 1 - Qualidade dos parâmetros físicos da saída da água do poço tubular (água de entrada no sistema a ser analisada no contexto ambiental

\begin{tabular}{|c|c|c|c|c|c|c|c|c|c|}
\hline \multirow[b]{2}{*}{ Parâmetros } & \multirow[b]{2}{*}{ Unidades } & \multirow{2}{*}{$\begin{array}{l}\text { IN-001/06 } \\
\text { (SUDERHSA) }\end{array}$} & \multicolumn{7}{|c|}{ Resultados analíticos } \\
\hline & & & $\begin{array}{l}09 / 2014 \\
\text { P1 }\end{array}$ & $\begin{array}{l}09 / 2014 \\
\text { P2 }\end{array}$ & $\begin{array}{l}03 / 2016 \\
\text { P1 }\end{array}$ & $\begin{array}{l}05 / 2016 \\
\text { P1 }\end{array}$ & $\begin{array}{l}\text { 08/2017 } \\
\text { P1 }\end{array}$ & Média & $\begin{array}{l}\text { Desvio } \\
\text { Padrão }\end{array}$ \\
\hline $\begin{array}{l}\text { Condutivida- } \\
\text { de Elétrica }\end{array}$ & $\mu \mathrm{S} . \mathrm{cm}^{-1}$ & - & 398,0 & 363,0 & 266,0 & 335,0 & 334,0 & 339,2 & 48,5 \\
\hline Dureza total & $\mathrm{mg} \cdot \mathrm{L}^{-1}$ & Até 500,0 & 77,6 & 156,2 & 96,1 & 145,2 & 145,2 & 124,06 & 34,9 \\
\hline $\mathrm{pH}$ & $\mathrm{UpH}$ & De 6,0 a 9,5 & 6,5 & 6,6 & 7,5 & 7,0 & 7,3 & 7,0 & 0,4 \\
\hline Turbidez & UNT & Até 5,0 & $<0,1$ & $<0,1$ & $<0,5$ & $<0,5$ & 0,9 & & \\
\hline Cor aparente & UH & Até 15,0 & 1 & $<1,0$ & $<1,0$ & 5,0 & $<5,0$ & & \\
\hline Gosto & $\begin{array}{c}\text { Intensida- } \\
\text { de }\end{array}$ & Até 6,0 & 1 & 3,0 & $<1,0$ & $<1,0$ & $<1,0$ & & \\
\hline Odor & $\begin{array}{c}\text { Intensida- } \\
\text { de }\end{array}$ & Até 6,0 & 1 & 3,0 & $<1,0$ & $<1,0$ & $<1,0$ & & \\
\hline Sólidos Totais & $\mathrm{mg} \cdot \mathrm{L}^{-1}$ & - & 316,0 & 284,0 & 209,0 & 270,0 & 222,0 & 260,2 & 44,3 \\
\hline $\begin{array}{l}\text { Sólidos Totais } \\
\text { Dissolvidos }\end{array}$ & $\mathrm{mg} \cdot \mathrm{L}^{-1}$ & Até 1.000 & 314,0 & 284,0 & 205,0 & 261,0 & 222,0 & 257,2 & 44,5 \\
\hline $\begin{array}{l}\text { Sólidos Sus- } \\
\text { pensos Totais }\end{array}$ & $m g \cdot L^{-1}$ & - & 0,0 & 0,0 & $<5,0$ & 9,0 & 0,0 & 2,25 & \\
\hline
\end{tabular}

Legenda: $\mu \mathrm{S} . \mathrm{cm}^{-1}$ - Micro Siemens por Centímetro; meq $\mathrm{L}^{-1}$ - Microequivalente grama por Litro; U pH - Unidade de $\mathrm{pH}$; UNT - Unidade Nefelométrica de Turbidez; UH - Unidade Hazen (1 uH = 1 mg Pt-Co.L-1), pela Portaria nº 518, de 2004, do Ministério da Saúde); mg. -1 $^{-1}$ - Miligrama por Litro; \% - Percentagem; P1 - Poço 1; P2 - Poço 2

Tabela2- Resultados obtidos para a Condutividade Elétrica

\begin{tabular}{|c|c|c|c|c|c|c|c|}
\hline \multirow[b]{2}{*}{ Parâmetros } & \multirow[b]{2}{*}{$\begin{array}{l}\text { Uni- } \\
\text { dades }\end{array}$} & \multirow{2}{*}{$\begin{array}{l}\text { IN-001/06 } \\
\text { (SUDERH- } \\
\text { SA) }\end{array}$} & \multicolumn{5}{|c|}{ Resultados analíticos } \\
\hline & & & $\begin{array}{l}\text { 09/2014 } \\
\text { P1 }\end{array}$ & $\begin{array}{l}\text { 09/2014 } \\
\text { P2 }\end{array}$ & $\begin{array}{l}\text { 03/2016 } \\
\text { P1 }\end{array}$ & $\begin{array}{l}\text { 05/2016 } \\
\text { P1 }\end{array}$ & $\begin{array}{l}\text { 08/2017 } \\
\text { P1 }\end{array}$ \\
\hline Condutividade Elétrica & $\mu S . c m^{-1}$ & - & 398,0 & 363,0 & 266,0 & 335,0 & 334,0 \\
\hline
\end{tabular}


formações predominantemente de granito, ou arenitos, a condutividade elétrica é extremamente baixa. Esse tipo de formação geológica não possui sais em sua formação. De forma totalmente contrária, solos de elevada concentração de argilas, os valores de condutividade são bastante altos (em torno de $400 \mathrm{uS} . \mathrm{cm}^{-1}$ ), para águas limpas, de superfícies ou oriundas de lençóis freáticos.

Muito embora as legislações não determinem valores para esse parâmetro, tem-se dentro da normalidade de águas de rios, um intervalo entre $15-800$ uS.cm ${ }^{-1}$, o que determina ser a água de entrada no sistema valores médios próximos de $300 \mathrm{uS} . \mathrm{cm}^{-1}$.

\section{Dureza Total}

A dureza da água reflete a presença de sais de metais alcalino terrosos, predominantemente cátions de cálcio e de magnésio. É, em outras palavras, a soma de cálcio e magnésio e é tida como uma medida da capacidade da água de precipitar sabão. Em concentrações elevadas consomem muito sabão na limpeza em geral, deixam resíduos insolúveis e causam corrosão e incrustações nas tubulações.

Dureza permanente refere-se à quantidade de magnésio e cálcio que permanecem na solução após a remoção da dureza temporária e está associada a anions sulfato, cloreto e nitrato.

Com base no que fora sintetizado na Tabela 1 , observa-se que em setembro de 2014 foram feitas análises de dois diferentes tipos de poços; e, para os anos de 2016 (nos meses de março e maio) e 2017 (em agosto), as amostras si concentraram para o poço $1(\mathrm{P} 1)$ e os valores para esse parâmetro tendem a apresentar, considerando os dois poços e todo o intervalo temporal, uma variação entre 77,6 e 156,2 mg.L.-1, quando o limite máximo aceitável sob a ótica ambiental estadual é de 500,0 mg.L-1.

Debruçando-se mais detalhadamente sobre os resultados do Poço 1 (P1) para o intervalo analisado, iniciou-se com a leitura de 77,6 em setembro/2014 e manteve-se estável no patamar de $145,2 \mathrm{mg} . \mathrm{L}^{-1}$, conforme extrato da Tabela 1, do parâmetro abaixo.

A dureza total não deverá ser inferior a $150 \mathrm{mg} \cdot \mathrm{L}^{-1} \mathrm{em}$ $\mathrm{CaCO}_{3}$. Assim, tendo em conta a importância deste parâmetro na proteção da saúde e das infraestruturas, é desejável que a dureza de uma água de consumo se situe entre 150 e $500 \mathrm{mg} . \mathrm{L}^{-1} \mathrm{de} \mathrm{CaCO}_{3}$.

\section{Potencial Hidrogeniônico-pH}

Utiliza-se o parâmetro do Potencial Hidrogeniônico para indicar o teor de íons hidrônio $\left(\mathrm{H}_{3} \mathrm{O}^{+}\right)$livres por unidade de volume da solução. Dessa forma, quanto mais hidrônios existirem no meio, mais ácida será a solução e menor será esse valor obedecendo uma escala que varia de 0,0 a 14,0, tendo o 7,0 como neutro. Assim, por analogia, quanto mais íons $\mathrm{OH}^{-}$houver no meio, mais básica ou alcalina será a solução. Apenas à título de curiosidade, este conceito foi introduzido em 1909 pelo químico dinamarquês Søren Peter LauritzSørensen.

$\mathrm{O}$ pH é importante, visto que o mesmo influi nos processos de potabilização e desinfecção da água. $\mathrm{O}$ pH é uma característica importante das águas de abastecimento, dada a sua influência na coagulação química, na desinfecção, no amolecimento de água e no controle da

Tabela 3- Resultados obtidos para a Dureza total

\begin{tabular}{|c|c|c|c|c|c|c|c|}
\hline \multirow[b]{2}{*}{ Parâmetros } & \multirow[b]{2}{*}{ Unidades } & \multirow{2}{*}{$\begin{array}{l}\text { IN-001/06 } \\
\text { (SUDERHSA) }\end{array}$} & \multicolumn{5}{|c|}{ Resultados analíticos } \\
\hline & & & $\begin{array}{l}\text { 09/2014 } \\
\text { P1 }\end{array}$ & $\begin{array}{l}\text { 09/2014 } \\
\text { P2 }\end{array}$ & $\begin{array}{l}\text { 03/2016 } \\
\text { P1 }\end{array}$ & $\begin{array}{l}\text { 05/2016 } \\
\text { P1 }\end{array}$ & $\begin{array}{l}\text { 08/2017 } \\
\text { P1 }\end{array}$ \\
\hline Dureza total & $m g \cdot L^{-1}$ & Até 500,0 & 77,6 & 156,2 & 96,1 & 145,2 & 145,2 \\
\hline
\end{tabular}

Tabela 4- Resultados obtidos para o $\mathrm{pH}$

\begin{tabular}{c|c|c|c|c|c|c|c}
\hline \multirow{3}{*}{ Parâmetros } & \multirow{3}{*}{ Unidades } & \multirow{2}{*}{$\begin{array}{l}\text { IN-001/06 } \\
\text { (SUDERHSA) }\end{array}$} & $\begin{array}{l}\text { Resultados analíticos } \\
\text { P1 }\end{array}$ & $\begin{array}{l}\text { 09/2014 } \\
\text { P2 }\end{array}$ & $\begin{array}{l}\text { 03/2016 } \\
\text { P1 }\end{array}$ & $\begin{array}{l}\text { 05/2016 } \\
\text { P1 }\end{array}$ & $\begin{array}{l}\text { 08/2017 } \\
\text { P1 }\end{array}$ \\
\hline $\mathrm{pH}$ & $\mathrm{U} \mathrm{pH}$ & De 6,0 a 9,5 & 6,5 & 6,6 & 7,5 & 7,0 & 7,3 \\
\hline
\end{tabular}

Tabela 5- Resultados obtidos para a Turbidez

\begin{tabular}{|c|c|c|c|c|c|c|c|}
\hline \multirow[b]{2}{*}{ Parâmetros } & \multirow[b]{2}{*}{$\begin{array}{l}\text { Uni- } \\
\text { dades }\end{array}$} & \multirow{2}{*}{$\begin{array}{l}\text { IN-001/06 } \\
\text { (SUDERH- } \\
\text { SA) }\end{array}$} & \multicolumn{5}{|c|}{ Resultados analíticos } \\
\hline & & & $\begin{array}{l}\text { 09/2014 } \\
\text { P1 }\end{array}$ & $\begin{array}{l}09 / 2014 \\
\text { P2 }\end{array}$ & $\begin{array}{l}\text { 03/2016 } \\
\text { P1 }\end{array}$ & $\begin{array}{l}\text { 05/2016 } \\
\text { P1 }\end{array}$ & $\begin{array}{l}\text { 08/2017 } \\
\text { P1 }\end{array}$ \\
\hline Turbidez & UNT & Até 5,0 & $<0,1$ & $<0,1$ & $<0,5$ & $<0,5$ & 0,9 \\
\hline
\end{tabular}


corrosão. $\mathrm{O}$ pH ácido pode levar à corrosão das tubulações e o pH básico diminui a eficiência do cloro na desinfecção da água (AGUAS GUARIROBA, 2017).

Com base no que fora extraído da Tabela 1 (exposto abaixo), observa-se que esse parâmetro apresenta uma flutuação temporal e espacial muito pequena, entre 6,5 e 7,3 comportando-se dentro do intervalo determinado pelo órgão ambiental que determina entre 6,0 e 9,5.

\section{Turbidez}

Por definição, entende-se que turbidez é a medida da dificuldade que um feixe de luz tem de atravessar certa quantidade de água, conferindo uma aparência turva à mesma. Essa medição é feita com o turbidímetro ou nefelômetro, que compara o espalhamento de um feixe de luz ao passar pela amostra, com o de um feixe de igual intensidade, ao passar por uma suspensão padrão. Quanto maior o espalhamento, maior será a turbidez.

Os valores são expressos, como no caso do referido relatório, normalmente, em Unidades Nefelométricas de Turbidez (UNT). O turbidimetro pode medir a turbidez em três escalas, cuja escala adotada para esse estudo é a 0-20 por buscar maior sensibilidade e a resolução é de 0,01 UNT.

Com base no extrato da Tabela 1 abaixo, observa-se que para esse parâmetro, os valores, em qualquer época ou ponto de coleta é muito abaixo do valor máximo apresentado pelo órgão ambiental.

Por se tratar de água subterrânea a água de entrada no sistema do curtume em estudo, a mesma apresenta características típicas com limites recomendados abaixo de $<1,0$ UNT.

\section{Cor Aparente}

A cor é geralmente um indicador da presença de metais (principalmente Fe e Mn), húmus (matéria orgânica oriunda da degradação de matéria de origem vegetal), plâncton (conjunto de plantas e animais microscópicos em suspensão nas águas), dentre outras substâncias dissolvidas na água.

A determinação de cor comumente é feita pela comparação visual com soluções de cloroplatinato de cobalto ou com discos de cor semelhantes à coloração das soluções de cloroplatinato de cobalto. É recomendável que seja feita no momento da coleta, evitando a estocagem o que poderia ocasionar variações no $\mathrm{pH}$.

Costuma-se definir cor aparente e a cor verdadeira.

A cor verdadeira se refere à determinação de cor em amostras sem turbidez (Ex.: após filtração ou centrifugação); e, a cor aparente se refere à determinação de cor em amostras com turbidez (com material coloidal ou em suspensão). Adotou-se pela análise da cor aparente considerando que a água de entrada, ao ser bombeada para o sistema agroindustrial apresenta as características reais associada, caso tenha, com a turbidez, na comentada em tópico específico acima.

A técnica de comparação com cloroplatinato é mais adequada à determinação de cor de águas de fontes naturais, mas não costuma ser adequada à determinação da cor de efluentes (onde, para casos dessa realidade, pós atividade agroindustrial) é possível variar a relação entre cloro e platina para ajustar a tonalidade da solução mas quando isso não é possível recomenda-se o uso de técnicas instrumentais (espectrofotometria).

Com base no extrato da Tabela 1 abaixo, observa-se que para esse parâmetro, os valores, em qualquer época ou ponto de coleta são muito baixos, ficando quase insignificantemente abaixo do valor máximo permitido apresentado pelo órgão ambiental estadual, muito embora tenha se registrado um aumento desse parâmetro para os dois últimos anos analisados, quando passou de $<1,0$ para 5,0 .

\section{Gosto e Odor}

De acordo com Magalhães ${ }^{1}$ (2016), a presença de gosto e odor desagradáveis na água, principalmente, para consumo humano é um problema crescente e complexo.

Muitos compostos químicos de origem industrial podem contribuir diretamente para gosto e odor na água. Por outro lado, esgotos domésticos, efluentes industriais e águas de drenagem urbana e agrícola contém nutrientes que estimulam a crescimento de organismos aquáticos. Substâncias produzidas por microrganismos e a decomposição da matéria orgânica em mananciais de abastecimento são fontes comuns de compostos causadores de gosto e odor na água potável.

A norma brasileira de qualidade da água para consumo humano do Ministério da Saúde, estabelece que gosto e odor devem fazer parte do padrão de potabilidade. Entretanto, os processos de tratamento chamados "convencionais" são pouco eficientes na remoção de muitos compostos que causam gosto e odor na água. As técnicas analíticas sofisticadas para a identificação e quantifica-

1 Adriana Barbosa Sales de Magalhães, Bióloga pela Universidade Estadual de Santa Cruz (UESC - Bahia), Mestrado e Doutorado em Botânica pela Universidade Federal de Viçosa (UFV) e Pós-doutorado em Saneamento Ambiental (UFV). Professora do Centro Universitário de Caratinga.

Tabela 6- Resultados obtidos para a Cor aparente

\begin{tabular}{|c|c|c|c|c|c|c|c|}
\hline \multirow[b]{2}{*}{ Parâmetros } & \multirow[b]{2}{*}{ Unidades } & \multirow{2}{*}{$\begin{array}{l}\text { IN-001/06 } \\
\text { (SUDERHSA) }\end{array}$} & \multicolumn{5}{|c|}{ Resultados analíticos } \\
\hline & & & $\begin{array}{l}\text { 09/2014 } \\
\text { P1 }\end{array}$ & $\begin{array}{l}\text { 09/2014 } \\
\text { P2 }\end{array}$ & $\begin{array}{l}\text { 03/2016 } \\
\text { P1 }\end{array}$ & $\begin{array}{l}\text { 05/2016 } \\
\text { P1 }\end{array}$ & $\begin{array}{l}\text { 08/2017 } \\
\text { P1 }\end{array}$ \\
\hline Cor aparente & $\mathrm{UH}$ & Até 15,0 & 1,0 & $<1,0$ & $<1,0$ & 5,0 & $<5,0$ \\
\hline
\end{tabular}


ção dos compostos orgânicos causadores de gosto e odor em águas de abastecimento não tem sido comuns entre a maioria das companhias de saneamento, uma vez que o investimento necessário em equipamentos e mão de obra altamente qualificada é significativamente elevado.

A qualidade da água dos mananciais tem sofrido alterações significativas, causadas pelo avançado estado de degradação. Isso pode interferir no gosto e odor, aspectos associados ao problema de rejeição da água.

De acordo com AWWA (1995), a grande evolução na identificação e tratamento de problemas de gosto e odor em águas de abastecimento ocorreu em 1965 quando os pesquisadores Gerber e LeChevalier isolaram e identificaram o composto Geosmina, produzido por culturas de actinomicetos, sendo estes causadores de gosto e odor de terra. Mais tarde, em 1969, Gerber isolou um segundo composto denominado 2-metilisoborneol (MIB), também produzido por culturas de actinomicetos.

Com base nos extratos da Tabela 1 para esses dois parâmetros, observa-se que os seus respectivos valores, sob a ótica espaço-temporal apresentam concentrações bem abaixo dos estabelecidos pela legislação estadual vigente. Com exceção da água oriunda do Poço 2 (P2) que fora utilizada como busca de fonte ainda em 2014.

\section{Sólidos Totais}

Segundo SABESP (1999), sólido total em água é o estado da matéria caracterizado pela rigidez, por uma forma própria e pela existência de um equilíbrio com o líquido proveniente da sua fusão. Por esta definição genérica podemos definir mais especificamente que toda substância que permaneça com as características acima, nas águas naturais e residuárias mesmo após várias operações como secagem e calcinação podem ser denominadas sólidos.

Existem várias classificações para sólidos em água mas, para esse estudo, nos concentraremos nos sólidos totais dissolvidos e sólidos suspensos totais, cujas interpretações estão avaliadas em separado, a seguir.
A Figura 1 apresenta a estratificação dos sólidos contidos na água em relação a metodologia adotada para análises de sólidos.

Ao tempo em que a Figura 2, apresenta a fragmentação desses sólidos mediante a metodologia 2540 B, C, D e E do Standard Methods (AWWA, 1998), contempla nove (9) frações diferentes de sólidos quantificáveis em uma amostra de matriz aquosa, que diferem entre si basicamente pelas suas características de tamanho de partícula e volatilidade.

São eles: sólidos totais (ST); sólidos dissolvidos totais (SDT); sólidos suspensos totais (SST); sólidos fixos totais (SFT); sólidos voláteis totais (SVT); sólidos dissolvidos fixos (SDF); sólidos dissolvidos voláteis (SDV); sólidos suspensos fixos (SSF); e, sólidos suspensos voláteis (SSV).

Muito embora a Legislação Ambiental do Estado não especifique um valor máximo permitido, observa-se pelo extrato da Tabela 1 focado para esse parâmetro, que os valores para o Poço 1 (P1) de captação de entrada de água, apresenta intervalos entre 222 a $316 \mathrm{mg} / \mathrm{L}$ onde, na sua totalidade, diz respeito ao sólidos totais dissolvidos, onde iremos melhor avalia-los, a seguir.

\section{Sólidos Totais Dissolvidos}

Os sólidos dissolvidos totais (ou SDT) são uma medida de todas as substâncias orgânicas e inorgânicas dissolvidas em um dado líquido, revelando a proporção de diferentes sólidos. Existe uma variedade de usos da SDT: ela pode mostrar se a água está pura ou poluída, por exemplo, e pode ser usada na agricultura, dentre outros fins.

Segundo SABESP (1999), consideram-se como STD todas as substâncias que não ficaram retidas na filtração e permaneceram após total secagem de determinado volume de amostra.

O referencial de potabilidade de uma amostra de água, para esse parâmetro STD, é de até $1.000 \mathrm{mg} \cdot \mathrm{L}^{-1}$. Dessa forma, como base no extrato da Tabela 1, observa-se que todas as leituras feitas nos Poços 1 e 2 ao longo do tempo, ficam bem abaixo dessa faixa limite.

\section{Tabela 7- Resultados obtidos para o Gosto e Odor}

\begin{tabular}{|c|c|c|c|c|c|c|c|}
\hline \multirow[b]{2}{*}{ Parâmetros } & \multirow[b]{2}{*}{ Unidades } & \multirow{2}{*}{$\begin{array}{l}\text { IN-001/06 } \\
\text { (SUDERH- } \\
\text { SA) }\end{array}$} & \multicolumn{5}{|c|}{ Resultados analíticos } \\
\hline & & & $\begin{array}{l}09 / 2014 \\
\text { P1 }\end{array}$ & $\begin{array}{l}\text { 09/2014 } \\
\text { P2 }\end{array}$ & $\begin{array}{l}03 / 2016 \\
\text { P1 }\end{array}$ & $\begin{array}{l}\text { 05/2016 } \\
\text { P1 }\end{array}$ & $\begin{array}{l}\text { 08/2017 } \\
\text { P1 }\end{array}$ \\
\hline Gosto & Intensidade & Até 6,0 & 1,0 & 3,0 & $<1,0$ & $<1,0$ & $<1,0$ \\
\hline Odor & Intensidade & Até 6,0 & 1,0 & 3,0 & $<1,0$ & $<1,0$ & $<1,0$ \\
\hline
\end{tabular}

Tabela 8- Resultados obtidos para os Sólidos Totais

\begin{tabular}{|c|c|c|c|c|c|c|c|}
\hline \multirow[b]{2}{*}{ Parâmetros } & \multirow[b]{2}{*}{ Unidades } & \multirow{2}{*}{$\begin{array}{l}\text { IN-001/06 } \\
\text { (SUDERH- } \\
\text { SA) }\end{array}$} & \multicolumn{5}{|c|}{ Resultados analíticos } \\
\hline & & & $\begin{array}{l}09 / 2014 \\
\text { P1 }\end{array}$ & $\begin{array}{l}\text { 09/2014 } \\
\text { P2 }\end{array}$ & $\begin{array}{l}\text { 03/2016 } \\
\text { P1 }\end{array}$ & $\begin{array}{l}05 / 2016 \\
\text { P1 }\end{array}$ & $\begin{array}{l}\text { 08/2017 } \\
\text { P1 }\end{array}$ \\
\hline Sólidos Totais & $m g . L^{-1}$ & - & 316,0 & 284,0 & 209,0 & 270,0 & 222,0 \\
\hline
\end{tabular}


Figura 1 - Relacionamento das análises de sólidos

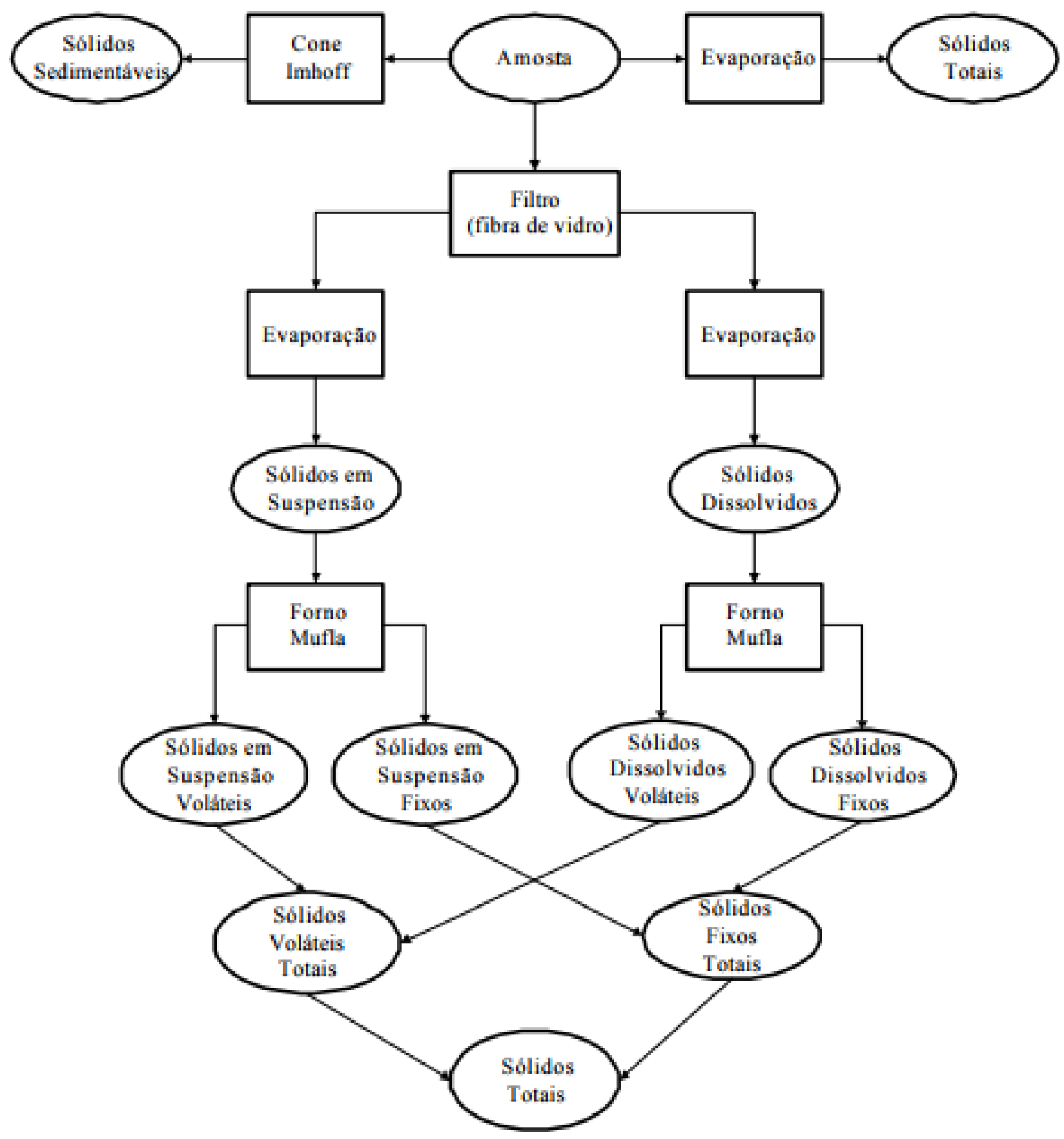

Fonte: Metcalf e Eddy (1991)

Tabela 9- Resultados obtidos para os Sólidos Totais Dissolvidos

\begin{tabular}{|c|c|c|c|c|c|c|c|}
\hline \multirow[b]{2}{*}{ Parâmetros } & \multirow[b]{2}{*}{ Unidades } & \multirow{2}{*}{$\begin{array}{l}\text { IN-001/06 } \\
\text { (SUDERHSA) }\end{array}$} & \multicolumn{5}{|c|}{ Resultados analíticos } \\
\hline & & & $\begin{array}{l}\text { 09/2014 } \\
\text { P1 }\end{array}$ & $\begin{array}{l}09 / 2014 \\
\text { P2 }\end{array}$ & $\begin{array}{l}\text { 03/2016 } \\
\text { P1 }\end{array}$ & $\begin{array}{l}\text { 05/2016 } \\
\text { P1 }\end{array}$ & $\begin{array}{l}\text { 08/2017 } \\
\text { P1 }\end{array}$ \\
\hline Sólidos Totais Dissolvidos & $\mathrm{mg} / \mathrm{L}$ & Até 1.000 & 314,0 & 284,0 & 205,0 & 261,0 & 222,0 \\
\hline
\end{tabular}


Figura 2 - Diagrama das 9 frações de sólidos obtidas no ensaio da "Série de Sólidos"

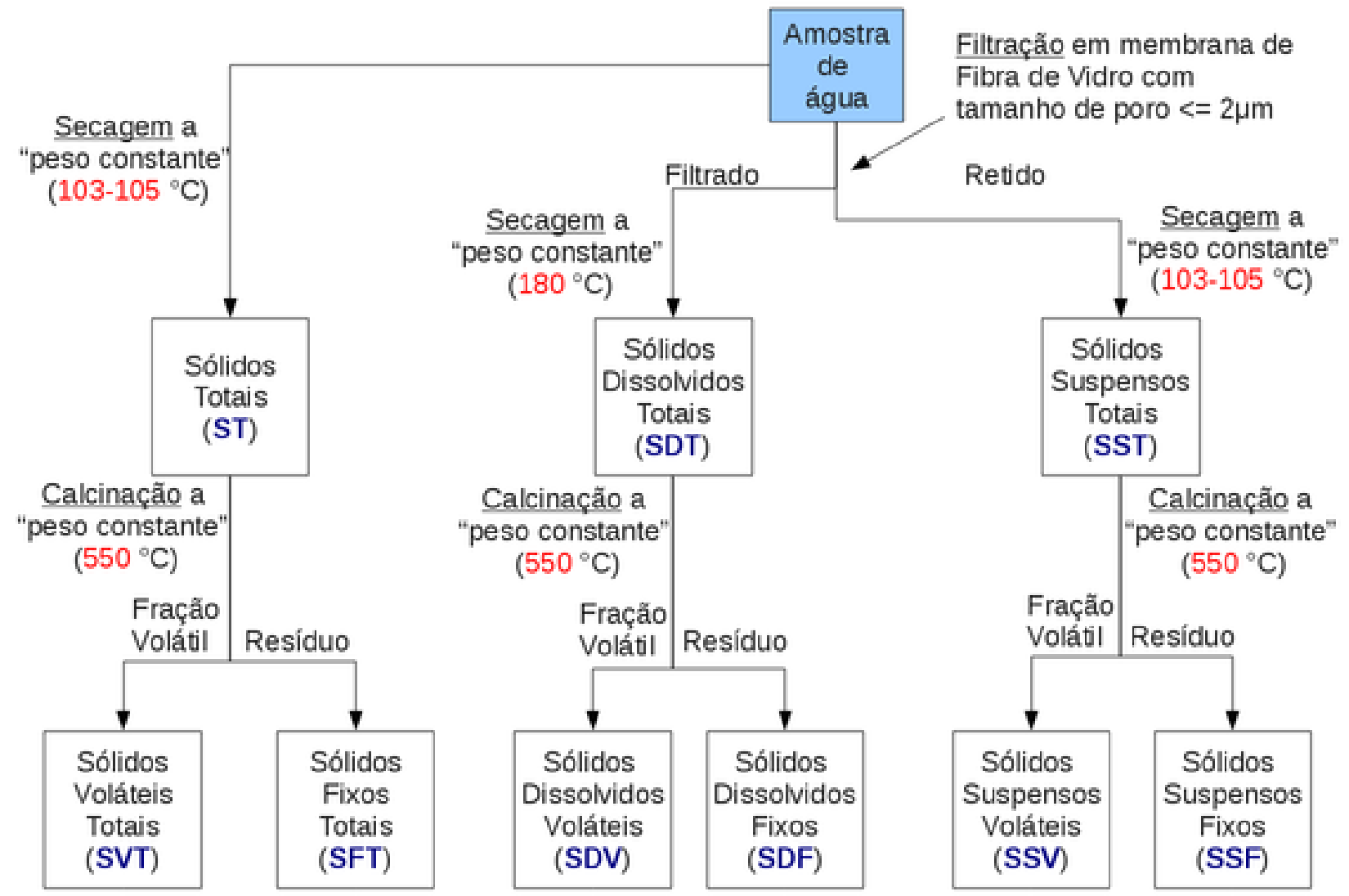

Tabela 10- Resultados obtidos para os Sólidos Suspensos Totais

\begin{tabular}{|c|c|c|c|c|c|c|c|}
\hline \multirow[b]{2}{*}{ Parâmetros } & \multirow[b]{2}{*}{ Unidades } & \multirow{2}{*}{$\begin{array}{l}\text { IN-001/06 } \\
\text { (SUDERHSA) }\end{array}$} & \multicolumn{5}{|c|}{ Resultados analíticos } \\
\hline & & & $\begin{array}{l}\text { 09/2014 } \\
\text { P1 }\end{array}$ & $\begin{array}{l}09 / 2014 \\
\text { P2 }\end{array}$ & $\begin{array}{l}\text { 03/2016 } \\
\text { P1 }\end{array}$ & $\begin{array}{l}\text { 05/2016 } \\
\text { P1 }\end{array}$ & $\begin{array}{l}\text { 08/2017 } \\
\text { P1 }\end{array}$ \\
\hline Sólidos Suspensos Totais & $m g \cdot L^{-1}$ & - & 0,0 & 0,0 & $<5,0$ & 9,0 & 0,0 \\
\hline
\end{tabular}

\section{Sólidos Suspensos Totais}

Os Sólidos Suspensos Totais (SST), é a medida que determina a quantidade de material particulado presente na água (SCHRYVER et al., 2008). Em outras palavras, são, segundo SABESP (1999), todas as substâncias que após filtração e secagem, permaneçam retidas na membrana (fibra de vidro com porosidade 1,2 $\mu \mathrm{m}$ ).

Existe uma íntima correlação entre SST e turbidez. Assim, como os valores para turbidez estão baixos, baixo são os valores para SST, mesmo não existindo nenhum valor máximo permitido estabelecido pelos órgãos de controle ambiental estadual. Os extratos da Tabela 1 para esse parâmetro confirmam o que fora apresentado a respeito.

\section{Conclusão}

Com base nos resultados das análises, pode-se concluir que para os parâmetros físicos, dureza total, $\mathrm{pH}$, condutividade elétrica, turbidez, cor aparente, gosto e odor, sólidos totais, sólidos totais dissolvidos, sólidos suspensos totais, encontram-se dentro dos limites máximos para consumo humano, referendado como de ótima qualidade.

A análise de tais parâmetros são essenciais não só para o controle da qualidade da água, mas também podem ser usados como indicadores ambientais. Dessa forma, novas análises periódicas devem ser realizadas a fim de se manter o controle ambiental e de promover a saúde dos indivíduos que trabalham ou habitam regiões próximas as áreas de curtumes.

Outro aspecto a ser considerado, é a análise da água proveniente de curtumes de outras regiões que poderiam ser comparadas no espaço e no tempo com o objetivo de encontrar fatores ou causas que proporcionam o desequilíbrio químico da amostra e propiciar ações que inibam tais causas.

A análise desses parâmetros é imprescindível para se conhecer e prever formas de controle que impeçam a contaminação da água proveniente de resíduos agroin- 
dustriais, em especial, da indústria química de curtume.

\section{Referências}

AGUAS GUARIROBAS. Qualidade da água. Disponível no endereço eletrônico: http://www.aguasguariroba.com. br/qualidade-agua/ e acessado em 31.out.2017.

AWWA - AMERICAN WATER WORKS ASSOCIATION. Advances in taste and odor treatment and control. Denver, AWWARF, 385p. 1995.

AWWA - AMERICAN WATER WORKS ASSOCIATION - [Standard Methods] 1998, 0-87553-235-7, American Water Works Association, Water Environment.

BRASIL. Conselho Nacional do Meio Ambiente. Resolução CONAMA no 396, de 3 de abril de 2008. Diário Oficial da União. 7 abr. 2008.

BRASIL.. Ministério da Saúde. Portaria do Ministério da Saúde no 2.914, de 12 de dezembro de 2011. Diário Oficial da União, 14 dez. 2011.

FREEZE, R.A.; CHERRY, J.A. Groundwater.N Jersey, Prentice-Hall inc., 1979, 604 p.

MAGALHÃES, A.B.S. Gosto e odor na água para consumo humano - um problema de saúde pública. 2016. Disponível no endereço eletrônico: https://www. diariodecaratinga.com.br/? $\mathrm{p}=18804$ e acessado em 31.out.2017.

\section{MANUAL TÉCNICOS PARA COLETA DE AMOSTRAS}

DE ÁGUA, Ministério Público de Santa Catarina. (s/d) Disponível no endereço eletrônico file://C:/Users/ admin/Downloads/livro-manual-tecnico-para-coleta-deamostras-de-agua-mp-sc.pdf e acessado em 29.out.2017.

METCALF \& EDDY, INC. Wastewater Engineering Treatment, disposal and reuse, third edition. McGrawHill book Co, 1991.

ROSA FILHO, E.F.; HINDI, E.C.; MANTOVANI, L.E.; BITTENCOURT, A.V.L.As Águassubterrâneas do Estado do Paraná.Curitiba: Maxi Gráfica, 2010.

ROSA FILHO, E.F.; HINDI, E.C.; MANTOVANI, L.E.; BITTENCOURT, A.V.L. Aquíferos do Estado do Paraná. Curitiba: Maxi Gráfica, 2011.

SABESP - Companhia de Saneamento Básico do Estado de São Paulo. Norma Técnica Interna SABESP NTS 013 SÓLIDOS Método de Ensaio. São Paulo Junho - 1999 Revisão 1.12 p.
SCHRYVER, P.D; CRAB, R.; DEFOIRDT, N.; BOON, W.The basics of bio-flocs technology: The added value for aquaculture. Aquaculture, v. 277, p. 125-137, 2008.

SILVA, A.W.; SILVA, F.F. Análise química da água de entrada no sistema agroindustrial de curtume em Maringá. REMOA, v. 17, p. 01-16, 2018.

\section{Contribuição dos autores}

\section{Marcelo Estevam}

Contribuições substanciais para a concepção do trabalho; aquisição, análise e interpretação de dados; redigiu o trabalho e realizou uma revisão substancial.

Adriano Willian da Silva

Contribuições substanciais para a concepção do trabalho; aquisição, análise e interpretação de dados; redigiu o trabalho e realizou uma revisão substancial.

Frederico Fonseca da Silva

Contribuições substanciais para a concepção do trabalho; aquisição, análise e interpretação de dados; redigiu o trabalho e realizou uma revisão substancial. 